\title{
STUDY ON THE DECONTAMINATION AND DESTRUCTION OF CHEMICAL WEAPONS THROUGH THE USE OF SIMULANTS
}

\author{
V. Ivanov ${ }^{1^{*}}$, N. Bozakova ${ }^{2}$, V. Petrova-Tacheva ${ }^{3}$, D. Zvezdova $^{4}$, V. Slavova ${ }^{1}$ \\ ${ }^{1}$ Department of Neurology, Psychiatry and MDS, Faculty of Medicine, Trakia University, \\ Stara Zagora, Bulgaria \\ ${ }^{2}$ Department of General Animal Breeding, Animal Hygiene, Ethology and Animal Protection Section. \\ Faculty of Veterinary Medicine, Trakia University, Stara Zagora, Bulgaria \\ ${ }^{3}$ Department of Molecular Biology, Immunology and Medical Genetics, Faculty of Medicine \\ Trakia University, Stara Zagora, Bulgaria \\ ${ }^{4}$ Department of Clinical and Pre-clinical Studies, Faculty of Health and Social Care, \\ Prof. Assen Zlatarov University, Burgas, Bulgaria
}

\begin{abstract}
Chemical weapons have been used repeatedly in the history of mankind in a number of wars and terrorist acts. They have caused serious damage on human health and taken many lives. In a number of cases, such as the development of antidotes against their action, doing research on their detection, also the development of sorbents for gas masks, and conducting military training, it is possible to use different simulants. These are compounds that resemble the action of the poisonous substances but lack such high toxicity. They are not so harmful to human life and health.

The purpose of this report is to explore the possibilities of using chemical warfare agents simulants to study their decontamination and destruction.
\end{abstract}

Key words: chemical warfare agent, tabun, sarin, soman, sulfur mustard

\section{INTRODUCTION}

Chemical weapons have been used on multiple cases in human history. They have caused serious harm to human health and killed many people. They pose a serious threat to the environment.

In some cases warfare agent stimulants can be used instead of the real substance, especially in scientific research on the mechanisms of toxic action; in the process of developing antidotes; when experimenting on and studying their resorption through the skin; when developing means of protection, decontamination solutions and lotions; when studying the process of degradation of real warfare agents; when developing means and methods of detection; when carrying out military training, etc. Warfare agent simulants have very similar manifestation of a particular real warfare agent but, at the same time, pose lower risk to

\footnotetext{
*Correspondence to: Veselin Ivanov, 11 Armeyska Str, 6000 Stara Zagora, Bulgaria, Phone: +35942664326, E-mail: veskoasenov@abv.bg
}

researchers, military staff and civilians. Their toxicity is lower and by rule, they are not that easily absorbed through the skin.

The team of authors has a rich experience in using simulants when researching the process of chemical warfare agents sorption in gas mask sorbents and in the eventual development of new sorbents.

The purpose of this paper is to present ways of using chemical warfare simulants, resembling the toxic action of real warfare agents but much less dangerous for the people involved for the purpose of investigation possibilities for their decontamination and destruction.

\section{Presentation}

Twenty-four volunteers took part in an interesting experiment. Their clothes, skin and hair were contaminated with ethyl lactate and methyl salicylate, liquid warfare agent stimulants. Decontamination was performed as the volunteers took a three-minute shower at water temperature of $30 \mathrm{C}$, after which their gas masks were removed. Thorough soap and 
water cleansing then followed. The final stage consisted of a simulation of first aid given to the volunteers. The experiment was carried out to demonstrate how decontamination procedures can be practiced as an exercise, without subjecting participants' lives and health to any risk (1). In a similar experiment, the volunteers' hair was contaminated with methyl salicylate and 2-chlor-ethyl ethyl sulfide, stimulants of sulfur mustard.

In order to investigate the resistance of the stimulants in the hair after intensive exposure to water steam, their desorption kinetics was studied applying two complementary methods: measuring the residuous quantity of stimulants in the hair and them measuring their quantity in the desorbed steam (2). Similar experiments of hair decontamination from the same stimulant substances were carried out by means of water showers, white clay, decontamination lotion and a combination of these (3). In another experiment methyl salicylate was used to study the skin decontamination properties of 15 products. In that experiment, the stimulant used emulated the effects of sulfur mustard (4).

Methyl salicylate is used as sulfur mustard and soman stimulant in experiments studying decontamination with chlorine based decontaminants. During such experiments the stechiometry, the effect of temperature, reaction time and $\mathrm{pH}$ have been studied. This suggests how useful that substance can be in scientific research, substituting highly toxic substances (5).

Polioxometalates can be added to liquids for surface skin protection. They can catalytically oxidize sulfur mustard. Sulfur mustard stimulants, added to perfluoropolyether are successfully used in experiments studying the decontamination polioxometalates (6).

Sulfur mustard stimulants 2-chlorethyl sulfide and 2-bromoethyl phenyl sulfide have been successfully used in experiments studying the decontamination kinetics of a mixture containing bovine hemoglobin, gelatin and poi (fermented taro root, a type of staple food in Hawaii) (7).

Diethyl malonate is used as soman stimulant. It replicates the way soman is resorbed through the skin, as well as its decontamination. This chemical compound has facilitated the process of determining a number of soman decontamination factors like water pressure and temperature; concentration of surface active substance in the decontamination liquid; the type of nozzle needed and the duration of the procedure (8).

The hypobromite ion, $\mathrm{BrO}(-)$ is an active nucleophil, which quickly reacts with 5valence phosphorus (V) and sulfonate esters. The acid it originates from oxidises organic sulfides and aryloxide ions. At $\mathrm{pH} 10-11, \mathrm{BrO}$ (-) and $\mathrm{HOBr}$ co-exist in water and are potentially useful as decontaminants for chlorosulfide blister agents and phosphonyle nerve agents. For the purpose of studying their decontamination effects, reactions with 4nitrophenyl diethyl phosphate and phosphonate, stimulants of nerve agents, can be used (9).

Sulfur mustard decomposition by a porphyrin metal-organic frame based catalyst is investigated using stimulant 2-chorethyl ethyl sulfide. The results have been compared with methods using hydrogen peroxide (10). The same substance has been used in another experiment - photo catalytic oxidation by a mixed type photo-catalyst, consisting of titanium oxide and silicon oxide (11), photocatalyst oxidation by a photo-catalyst on the base of Zr-benzothiadiazole and benzoselendiazole containing metal organic frames (12).

Sulfur mustard degradation by charcoal, impregnated with 11-molibdenum-1 vanadophosphorus acid, with rutenum chloride or with a combination of the two can be tested by using simulants dibutyl sulfide and ethyl 2hydroxiethyl sulfide (13).

In laboratory experiments on the degradation of nerve agents sarin and VX in a reactor by oxidation with hydrogen peroxide, simulant dimethyl methylphosphonate can be successfully used. This chemical compound has a structure similar to chemical warfare agents. The experiments were carried out in an isothermal tube reactor. Reaction temperatures vary between 398 and $633^{\circ} \mathrm{C}$, at pressure fixed at $24 \mathrm{MPa}$. Based on experiment data, a kinetic equilibrium on dimethyl methylphosphonate degradation has been worked out (14).

2- (butylamino)ethanethyol is considered a VX simulant. The compound is used in experiments studying photo-catalyst oxidation by titanium dioxide and degradation by ultrasound (15).

Malathion can be used as a simulant when studying $\mathrm{Vx}$ enzyme hydrolysis (16). Triethylphosphate is used as a simulant in experiments studying the degradation of 
IVANOV V., et al.

chemical nerve agent (17). Diethylphosphonate can be used as tabun simulant when investigating its photocatalytic degradation (18).

\section{CONCLUSION}

In many cases in scientific research simulants can be used to investigate the process of decontamination and degradation of chemical warfare agents. This does not affect the quality of experiments and results but substantially diminishes the risk of accidents and provides safe environment for the researchers involved.

\section{ACKNOWLEDGEMENTS}

This article has been supported by scientific projects №7/2016 of Medical faculty, Trakia University.

\section{REFERENCES}

1. Törngren S ., Persson SA, Ljungquist A, Berglund $\mathrm{T}$, Nordstrand $\mathrm{M}$, Hägglund $\mathrm{L}$, Rittfeldt L, Sandgren K, Söderman E. Personal decontamination after exposure to stimulated liquid phase contaminants: functional assessment of a new unit. $J$ Toxicol Clin Toxicol. 36(6):567-73, 1998.

2. Spiandore M., Souilah-Edib M., Piram A ., Lacoste A ., Josse D ., Doumenq P. Desorption of sulphur mustard simulants methyl salicylate and 2-chloroethyl ethyl sulphide from contaminated scalp hair after vapour exposure. Chemosphere. 191:721-728, 2018.

3. Spiandore M ., Piram A ., Lacoste A ., Prevost P ., Maloni P ., Torre F., Asia L ., Josse D ., Doumenq P. Efficacy of scalp hair decontamination following exposure to vapours of sulphur mustard simulants 2chloroethyl ethyl sulphide and methyl salicylate. Chem Biol Interact. 267:74-79, 2017.

4. Matar H ., Guerreiro A ., Piletsky SA ., Price SC ., Chilcott RP. Preliminary evaluation of military, commercial and novel skin decontamination products against a chemical warfare agent simulant (methyl salicylate). Cutan Ocul Toxicol. 35(2):137-44, 2016.

5. Salter WB ., Owens JR, Wander JD. Methyl salicylate: a reactive chemical warfare agent surrogate to detect reaction with hypochlorite. ACS Appl Mater Interfaces. 3(11):4262-7, 2011.

6. Johnson $\mathrm{RP}^{1}$, Hill CL. Polyoxometalate oxidation of chemical warfare agent simulants in fluorinated media. J Appl Toxicol. 19 Suppl 1:S71-5, 1999.

7. Cerny LC ${ }^{1}$, Cerny ER. The effect of biological media on the hydrolysis of mustard simulants. Biomed Sci Instrum. 33:535-40, 1997.

8. Reifenrath WG, Mershon MM, Brinkley FB, Miura GA, Broomfield CA, Cranford HB.
Evaluation of diethyl malonate as a simulant for 1,2,2-trimethylpropyl methylphosphonofluoridate (soman) in shower decontamination of the skin. J Pharm Sci. 73(10):1388-92, 1984.

9. Simanenko YS., Savelova VA, Prokop'eva TM, Mikhailov VA, Turovskaya MK, Karpichev EA, Popov AF, Gillitt ND, Bunton CA. Bis(dialkylamide)hydrogen dibromobromate precursors of hypobromite ion in reactions with nerve and blister agent simulants. J Org Chem. 69(26):9238-40, 2004.

10.Liu Y ., Howarth AJ ., Hupp JT ., Farha OK . Selective Photooxidation of a Mustard-Gas Simulant Catalyzed by a Porphyrinic MetalOrganic Framework. Angew Chem Int Ed Engl. 54(31):9001-5, 2015.

11.Panayotov D ., Kondratyuk P, Yates JT Jr. Photooxidation of a mustard gas simulant over $\mathrm{TiO} 2-\mathrm{SiO} 2$ mixed-oxide photocatalyst: site poisoning by oxidation products and reactivation. Langmuir. 20(9):3674-8, 2004.

12. Goswami S, Miller CE, Logsdon JL, Buru $\mathrm{CT}, \mathrm{Wu}$ YL, Bowman DN ., Islamoglu T, Asiri AM, Cramer CJ, Wasielewski MR, Hupp JT, Farha OK. Atomistic Approach toward Selective Photocatalytic Oxidation of a Mustard-Gas Simulant: A Case Study with Heavy-Chalcogen-Containing PCN-57 Analogues. ACS Appl Mater Interfaces. 9(23):19535-19540, 2017.

13. Sharma A ., Saxena A, Singh B, Sharma M, Suryanarayana MV, Semwal RP, Ganeshan K, Sekhar K. In-situ degradation of sulphur mustard and its simulants on the surface of impregnated carbon systems. J Hazard Mater. 133(1-3):106-12, 2006.

14. Veriansyah $\mathrm{B}^{1}$, Kim JD, Lee YW. Decomposition kinetics of dimethyl methylphospate (chemical agent simulant) by supercritical water oxidation. J Environ Sci (China). 18(1):13-6, 2006.

15. Vorontsov $\mathrm{AV}^{1}$, Chen YC, Smirniotis PG. Photocatalytic oxidation of VX simulant 2(butylamino)ethanethiol. J Hazard Mater. 113(1-3):89-95, 2004.

16. Hoskin FC ., Walker JE. Malathion as a model for the enzymatic hydrolysis of the neurotoxic agent, VX. Bull Environ Contam Toxicol. 59(1):9-13, 1997.

17. Pascal S ., Moussa D, Hnatiuc E, Brisset JL. Plasma chemical degradation of phosphorouscontaining warfare agents simulants. $J$ Hazard Mater. 175(1-3):1037-41, 2010.

18. Kolinko PA ${ }^{1}$, Kozlov DV. Photocatalytic oxidation of tabun simulant-diethyl cyanophosphate: FTIR in situ investigation. Environ Sci Technol. 42(12):4350-5, 2008. 